\title{
ISOLASI FUNGI ENDOFIT PENGHASIL ANTIBIOTIKA PADA ALGA MERAH JENIS Gracilaria verrucosa SECARA KLT-BIOAUTOGRAFI
}

\author{
Herwin \\ Fakultas Farmasi Universitas Muslim Indonesia, Makassar \\ Email : herwinfarmasi@gmail.com
}

\begin{abstract}
This research aimed to determine the antibacterial fungi endofitic isolate of Gracilaria verrucosa type Rhodophyta that antibiotic as potential by BioautographyTLC Method. The result of fungi endofitic isolate, obtained that 7 active isolates and purified by quadrant method on potato dextrose agar medium obtained 5 active isolates (isolate 1, 2, 3, 5, 6). The result of the screening of fungi endofitic isolate by cakram method possessed that the biggest inhibitory zone is isolate 2 and isolate 6 by $25 \mathrm{~mm}$ at Streptococcus mutans. The test results of fungi endofitic isolate activity by Bioautography-TLC obtained Rf 0.07 0.23, 0.56, 0.78, 0.81 and 0.94 value actif inhibited Bacillus subtilis, Shigella disentry, Streptococcus mutans and Eschericia coli. And the identification results of the chemical component shown that the actif compound at isolate 2 and isolate 6 given result positif alkaloid.
\end{abstract}

Key words : Ethanol extract of stem Phytocrene macrophylla Blume, agar diffusion, antibacterial.

\section{PENDAHULUAN}

Penggunaan antibiotika di dunia lebih dari 40.000 ton/tahun dalam industri pangan, pakan, pertanian, kesehatan, biokimia, genetika, dan biologi molekuler serta ada kecenderungan untuk terus meningkat dan dapat menimbulkan resistensi terhadap mikroba target. ${ }^{1}$ Oleh karena itu, langkah-langkah mendapatkan jenis antibiotika baru masih sangat diperlukan baik lewat sintesis kimia, biokimia baru atau penemuan isolat mikrobia baru. ${ }^{2}$

Dalam dua dekade terakhir ini, fungi endofit merupakan salah satu sumber utama mikroba penghasil antibiotika baru. $^{3}$ Mikroba endofit adalah organisme hidup yang berukuran mikroskopis (bakteri dan jamur) yang hidup di dalam jaringan tanaman (xylem dan phloem), daun, akar, buah, dan batang. Mikroba endofit yang terdiri atas bakteri dan 
Isolasi fungi endofit penghasil antibiotika pada alga merah jenis Gracilaria verrucosa secara $K L T$-Bioautografi

jamur merupakan mikroba yang hidup di dalam jaringan tanaman dan membentuk koloni tanpa membahayakan inangnya. Kemampuan mikroba endofit memproduksi senyawa metabolit sekunder sesuai dengan tanaman inangnya yang merupakan peluang sangat besar dan dapat diandalkan untuk memproduksi metabolit sekunder dari mikroba endofit yang diisolasi dari tanaman inangnya. ${ }^{4}$

Salah satu tumbuhan yang dapat dimanfaatkan sebagai sumber antibiotika adalah alga merah jenis Gracilaria verrucosa. Banyak jenis alga yang berpotensi untuk diteliti dan dikembangkan pemanfaatannya sebagai sumber obat. Alga memiliki kandungan metabolit primer dan sekunder. Kandungan metabolit sekunder dari alga berpotensi sebagai penghasil metabolit bioaktif yang beragam dengan aktivitas yang sangat luas sebagai antibakteri, antivirus, anti jamur dan sitotastik. ${ }^{5}$

Alga merupakan salah satu bahan alami yang tidak menimbulkan resistensi untuk mengatasi penyakit pada makhluk hidup karena memiliki metabolit sekunder yang dapat menghambat/membunuh

pertumbuhan bakteri, sehingga dilakukan penelitian isolasi fungi endofit penghasil antibiotika pada Alga Merah jenis Gracilaria verrucosa asal Belopa secara KLT-bioautografi.

\section{METODE PENELITIAN}

\section{Alat dan Bahan}

Alat yang digunakan pada penelitian ini adalah autoklaf, cawan petri, chamber, enkas, inkubator (Memmert®), LAF (Laminar Air Flow), lampu UV 254 nm dan 366 nm, oven (Fisher®). Bahan yang digunakan pada penelitian ini adalah bakteri uji (Escherichia coli, Basillus subtilis, Streptococcus mutans, dan Shigella disentry), etil asetat, isolat fungi endofit Alga Merah jenis Gracilaria verrucosa, lempeng KLT, medium Nutrient Agar (NA), medium Potato Dextrosa Agar (PDA), medium Potato Dextrosa Agar chloramphenicol (PDAC), medium Maltosa Yeast Broth (MYB), n-heksan dan pereaksi golongan (Dragendrof$\mathrm{HCl}$, bauchardat, Sitroboraks dan $\mathrm{FeCl}_{3}$ ).

\section{Prosedur Penelitian}

\section{Isolasi Fungi Endofit Dari Alga}

\section{Merah Jenis Gracilaria verrucosa}

Alga Merah jenis Gracilaria verrucosa yang telah disortasi basah disterilisasi permukaan menggunakan etanol $70 \%$ selama $2-5$ menit, selanjutnya dibilas dengan aquadest steril \pm 1 menit diulang 2-3 kali lalu dikeringkan. Pengerjaan dilakukan 
Isolasi fungi endofit penghasil antibiotika pada alga merah jenis Gracilaria verrucosa secara KLT-Bioautografi

secara aseptis di dalam Laminar Air Flow (LAF). Potongan kecil Gracilaria verrucosa diletakkan diatas medium PDAC (PDA+Cloramphenicol) di dalam cawan petri steril yang kemudian diinkubasi di dalam inkubator pada suhu kamar $\left(25^{\circ} \mathrm{C}-30^{\circ} \mathrm{C}\right)$ selama 3 hari. Diisolasi dan dimurnikan pada media PDAC baru untuk mendapatkan biakan murni. ${ }^{4}$

\section{Pemurnian Isolat Fungi Endofit}

Setiap isolat yang berbeda dimurnikan dengan metode quadrant streak, kemudian diinkubasi di dalam inkubator pada suhu $25^{\circ} \mathrm{C}-30^{\circ} \mathrm{C}$ selama 3 hari untuk memperoleh isolat tunggal. Isolat murni yang diperoleh diinokulasi pada agar miring sebagai stok. ${ }^{6}$

\section{Pemeriksaan Makroskopik Isolat Fungi Endofit}

Setiap isolat diambil 1 ose diinokulasi kedalam medium PDAC, kemudian diinkubasi selama 3 hari pada suhu $25^{\circ} \mathrm{C}$, lalu dilakukan pengamatan terhadap bentuk, tepi, elevasi dan warna koloni pada medium PDAC.

\section{Uji Skrining Aktivitas Antibakteri Fungi Endofit}

Pengujian isolat fungi endofit dilakukan secara dilusi padat. Semua isolat fungi alga ditumbuhkan kedalam medium PDAC, kemudian cakram fungi alga yang berumur 3 hari inkubasi pada medium PDAC ditempatkan di dalam cawan petri pada permukaan medium Nutrien Agar yang telah bercampur dengan mikroba uji. Selanjutnya di inkubasi selama 1 hari pada suhu $37^{\circ} \mathrm{C} .^{4}$

\section{Fermentasi isolat}

Diambil isolat aktif menggunakan ose dimasukkan ke dalam gelas erlenmeyer yang berisi $250 \mathrm{~mL}$ medium MYB, selanjutnya dilakukan fermentasi menggunakan rotary shaker dengan kecepatan 200 rpm pada suhu kamar selama 14 × 24 jam hingga diperoleh fermentat berupa supernatan dan miselia. Fermentat supernatan yang diperoleh diekstraksi dengan menggunakan pelarut etil asetat hingga diperoleh ekstrak etil asetat isolat supernatan.

\section{Uji Aktivitas Antibiotika Secara KLT - Bioautografi}

Lempeng kromatografi lapis tipis diaktifkan terlebih dahulu dengan pemanasan menggunakan oven pada suhu $100^{\circ} \mathrm{C}$ selama 30 menit. Ekstrak etil asetat isolat supernatan Alga Merah jenis Gracilaria verrucosa ditotolkan pada lempeng KLT berukuran $7 \times 1 \mathrm{~cm}$ menggunakan pipa kapiler. Kemudian dielusi chamber menggunakan fase gerak n-heksan : etil asetat (1: 5) kemudian 
Isolasi fungi endofit penghasil antibiotika pada alga merah jenis Gracilaria verrucosa secara KLT-Bioautografi

kromatogram yang diperoleh dilakukan pengamatan bercak pada sinar UV $254 \mathrm{~nm}$ dan $366 \mathrm{~nm}$. Kromatogram yang diperoleh dilakukan pengujian aktivitas antibiotika secara KLTBioautografi dengan cara sebanyak 10 $\mathrm{mL}$ medium NA dimasukkan kedalam cawan petri dan ditambahkan suspensi bakteri sebanyak $20 \quad \mu \mathrm{L}$ lalu dihomogenkan, lempeng kromatogram diletakkan diatas permukaan medium agar yang telah diinokulasikan dengan mikroba uji kemudian dibiarkan selama 60 menit. Setelah itu lempeng diangkat dan dikeluarkan, selanjutnya diinkubasi selama $1 \times 24$ jam pada suhu $37^{\circ} \mathrm{C}$ kemudian diamati bercak yang memberikan aktivitas penghambatan terhadap pertumbuhan

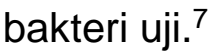

\section{Identifikasi komponen kimia}

Golongan Alkaloid : Pereaksi

Dragendrof- $\mathrm{HCl}$ dengan cara lempeng kromatogram disemprot. Tampak bercak berwarna jingga sampai coklat dan pereaksi Bauchardat dengan cara lempeng kromatogram disemprot dan menghasilkan tampak bercak berwarna coklat.

Golongan Fenol : Besi (III) klorida dengan cara lempeng kromatogram disemprot dengan $\mathrm{FeCl}_{3}$ sampai tampak bercak berwarna biru, biru kehitaman, hijau atau biru tua.

Golongan Flavanoid : Pereaksi Sitroborat dengan cara lempeng kromatogram disemprot dimana positif flavonoid jika terjadi perubahan warna flourosensi hijau kuning pada lempeng KLT yang divisualisasi pada lampu UV $366 \mathrm{~nm}$.

\section{Pengumpulan Data Dan Analisis Data}

Data yang diperoleh dari hasil penelitian dilakukan pengumpulan data berdasarkan hasil isolasi fungi endofit, skrining aktivitas antibiotika, pengujian aktivitas antibiotika secara KLTBioautografi dan identifikasi golongan komponen kimia aktif dianalisis berdasarkan aktifitas antibiotika isolat fungi endofit Alga Merah Jenis Gracilaria verrucosa yang dapat menghambat pertumbuhan bakteri uji. 
Isolasi fungi endofit penghasil antibiotika pada alga merah jenis Gracilaria verrucosa secara $K L T$-Bioautografi

\section{HASIL PENELITIAN}

Tabel 1. Hasil pemurnian isolat fungi endofit alga merah jenis Gracilaria verrucosa dengan metode kuadran

\begin{tabular}{ccc}
\hline No. & Kode fungi endofit & Biakan fungi \\
\hline 1. & IFM 1 & Biakan fungi ke-1 \\
2. & IFM 2 & Biakan fungi ke-2 \\
3. & IFM 3 & Biakan fungi ke-3 \\
4. & IFM 4 & Biakan fungi ke-4 \\
5. & IFM 5 & Biakan fungi ke-5 \\
6. & IFM 6 & Biakan fungi ke-6 \\
7. & IFM 7 & Biakan fungi ke-7 \\
\hline Keterangan & &
\end{tabular}

IFM 1 : Isolat fungi endofit ke-1 IFM 3 : Isolat fungi endofit ke-3 IFM 5 : Isolat fungi endofit ke-5 IFM 7 : Isolat fungi endofit ke-7
IFM 2 : Isolat fungi endofit ke-2

IFM 4 : Isolat fungi endofit ke-4

IFM 6 : Isolat fungi endofit ke-6

Tabel 2. Hasil makroskopik isolat fungi endofit pada alga merah jenis Gracilaria verrucosa

\begin{tabular}{ccccc}
\hline Kode Bakteri & Warna & Bentuk & Tepi & Elevasi \\
\hline IFM 1 & Putih & Bulat & Utuh & Timbul Datar \\
IFM 2 & Putih & Tidak Teratur & Utuh & Cembung \\
IFM 3 & Putih & Tidak Teratur & Utuh & Timbul Datar \\
IFM 4 & Putih & Bulat & Berbenang & Membukit \\
IFM 5 & Putih & Tidak Teratur & Utuh & Serupa Kawah \\
IFM 6 & Putih & Tidak Teratur & Utuh & Membukit \\
IFM 7 & Putih & Tidak Teratur & Utuh & Cembung \\
\hline
\end{tabular}

Keterangan :

IFM 1 : Isolat fungi endofit ke-1

IFM 3 : Isolat fungi endofit ke-3

IFM 5 : Isolat fungi endofit ke-5

IFM 7 : Isolat fungi endofit ke-7

IFM 2 : Isolat fungi endofit ke-2

IFM 4 : Isolat fungi endofit ke-4

IFM 6 : Isolat fungi endofit ke-6

Tabel 3. Hasil uji skrining aktivitas isolat fungi endofit dari alga merah jenis Gracilaria verrucosa terhadap beberapa bakteri uji.

\begin{tabular}{|c|c|c|c|c|c|c|}
\hline \multirow{2}{*}{ NO } & \multirow{2}{*}{ Isolat Fungi Endofit } & \multirow{2}{*}{ Replikasi } & \multicolumn{4}{|c|}{ Diameter Zona Hambatan (mm) } \\
\hline & & & SD & SM & BS & EC \\
\hline \multirow{4}{*}{1} & \multirow{4}{*}{ IFM 1} & 1 & 22 & 25 & 22 & 17 \\
\hline & & 2 & 23 & 24 & 23 & 21 \\
\hline & & 3 & 22 & 24 & 23 & 18 \\
\hline & & Rata-rata & 22 & 24 & 22 & 18 \\
\hline \multirow{4}{*}{2} & \multirow{4}{*}{ IFM 2} & 1 & 24 & 27 & 28 & 18 \\
\hline & & 2 & 25 & 25 & 26 & 18 \\
\hline & & 3 & 24 & 25 & 23 & 20 \\
\hline & & Rata-rata & 24 & 25 & 25 & 18 \\
\hline \multirow{4}{*}{3} & \multirow{4}{*}{ IFM 3} & 1 & 22 & 25 & 24 & 22 \\
\hline & & 2 & 24 & 22 & 24 & 21 \\
\hline & & 3 & 26 & 23 & 23 & 21 \\
\hline & & Rata-rata & 24 & 23 & 23 & 21 \\
\hline
\end{tabular}


Isolasi fungi endofit penghasil antibiotika pada alga merah jenis Gracilaria verrucosa secara KLT-Bioautografi

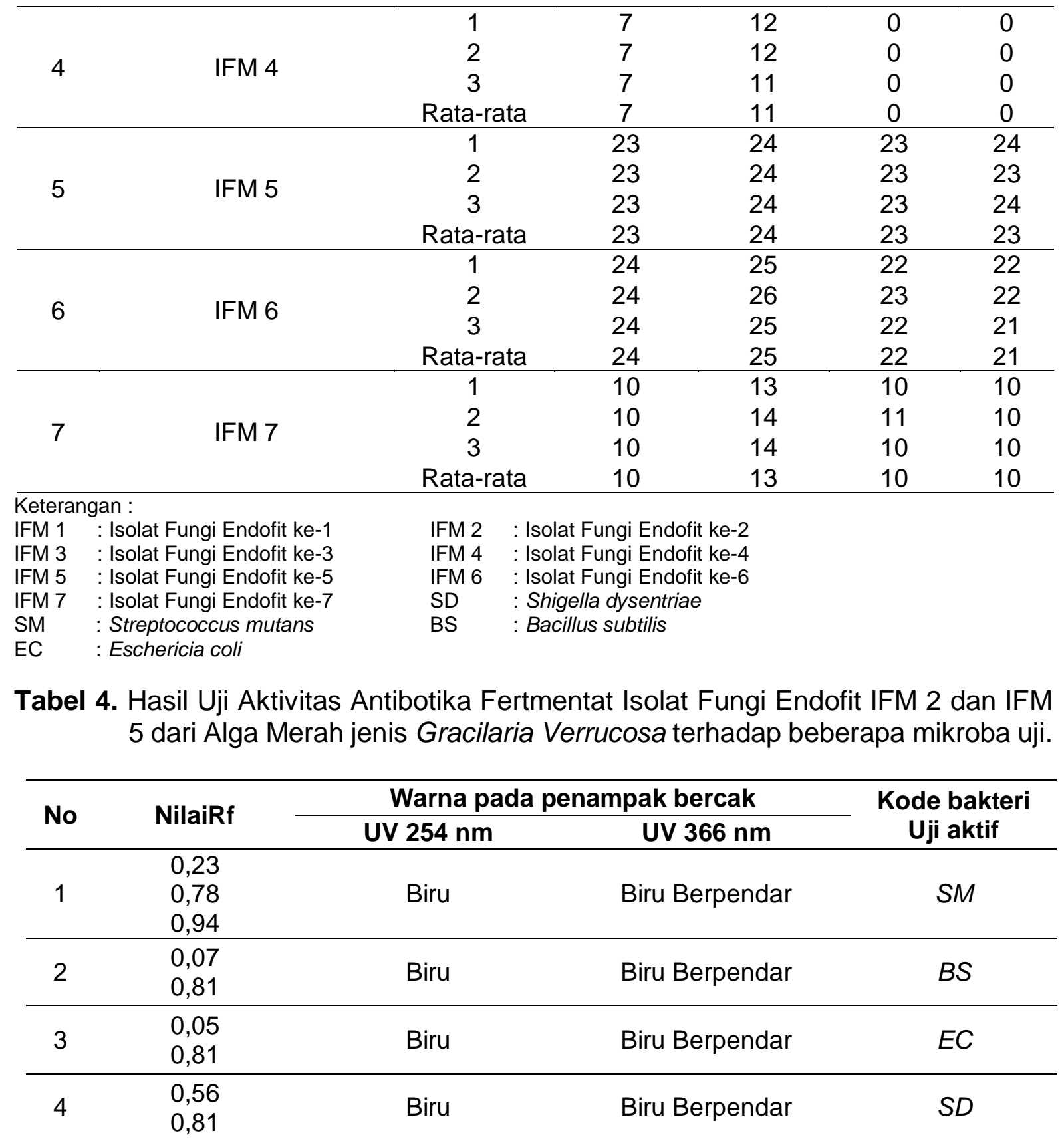

Keterangan :

SM : Streptococcus mutans, BS : Bacillus subtilis, EC : Eschericia coli, SD : Shigella dysentriae

Tabel 5. Hasil Identifikasi komponen kimia Isolat Fungi Endofit IFM 2 dan IFM 5 dari Alga Merah jenis Gracilaria Verrucosa

\begin{tabular}{ccc}
\hline No. & Warna & Pereaksi \\
\hline 1. & Kuning & Dragendrof $(-)$ \\
2. & Coklat & Bauchardard $(+)$ \\
3. & Coklat & FeCl $_{3}(-)$ \\
4. & Coklat & Sitroborat $(+)$ \\
\hline Keterangan : (+): Mengandung Senyawa Kimia Aktif Alkaloid & \\
\hline
\end{tabular}

Keterangan : (+) : Mengandung Senyawa Kimia Aktif Alkaloid

(-) : Tidak mengandung senyawa kimia aktif 
Isolasi fungi endofit penghasil antibiotika pada alga merah jenis Gracilaria verrucosa secara $K L T$-Bioautografi

\section{PEMBAHASAN}

Alga merupakan Salah satu tumbuhan laut yang sering digunakan untuk bahan pangan, bahan kosmetik dan pengobatan tradisional oleh masyarakat Indonesia, yang telah diteliti sebagai sumber antibiotika, dari hasil penelitian sebelumnya ekstrak dari alga mampu membunuh beberapa bakteri. Dalam upaya untuk memperoleh senyawa antibiotika baru maka pada penelitian ini, dilakukan penelusuran komponen kimia aktif antibiotika dari fungi endofit pada Alga Merah jenis Gracilaria verrucosa asal Belopa secara KLT-Bioautografi.

Penelitian ini mengisolasi fungi endofit yang memiliki aktivitas sebagai antibiotika dari Alga merah jenis Gracilaria verrucosa sebagai sumber penghasil antibiotika. Alga ini telah diketahui dari berbagai macam penelitian memiliki beberapa macam aktivitas, selain sebagai antioksidan Alga Merah jenis Gracilaria verrucosa juga memiliki potensi sebagai antiinflamasi. Fungi endofit merupakan fungi yang tumbuh dan bersimbiosis dalam jaringan tumbuhan. Fungi endofit ini diduga bersimbiosis dan bermutasi dalam jaringan tumbuhan dalam hal ini Alga Merah jenis Gracilaria verrucosa. Hasil isolasi fungi endofit diperoleh 7 isolat yang diduga berpotensi sebagai antibiotika. Isolat yang diperoleh dilakukan pemurnian dengan metode kuadran yang diberi kode IFM 1 untuk biakan fungi ke-1, IFM 2 untuk biakan fungi ke-2, IFM 3 untuk biakan fungi ke-3, IFM 4 untuk biakan fungi ke-4, IFM 5 untuk biakan fungi ke-5, IFM 6 untuk biakan fungi ke6, dan IFM 7 untuk biakan fungi ke-7, isolat yang diperoleh diinokulasikan ke medium PDAC miring sebagai stok.

$$
\text { Hasil skrining aktivitas }
$$

antibiotika menunjukkan bahwa isolat fungi endofit IFM 1, IFM 2, IFM 3, IFM 5, IFM 6, dan IFM 7 memberikan aktivitas terhadap Shygella dysentriae, Streptococcus mutans, Bacillus subtilis, dan Escherichia coli. Sedangkan isolat fungi endofit IFM 4 tidak memberikan aktivitas terhadap Bacillus subtilis, dan Escherichia coli. Dari hasil skrining tersebut menunjukkan isolat fungi endofit IFM 2 dan IF 6 memberikan aktivitas yang paling baik terhadap beberapa bakteri uji Gram positif yaitu Streptococcus mutans dengan diameter zona hambatan sebesar 25 $\mathrm{mm}$.

Isolat murni dengan kode IFM 2 dan IFM 6 difermentasi dalam medium Maltosa Yeast Broth (MYB) selama 14 x 24 jam, sambil dishaker dengan kecepatan 200 rpm agar selama proses fermentasi fungi endofit ini akan 
Isolasi fungi endofit penghasil antibiotika pada alga merah jenis Gracilaria verrucosa secara KLT-Bioautografi

mencapai fase stationer dan menghasilkan metabolit sekunder diperoleh fermentat supernatan dan miselia. Fermentat supernatan IFM 2 dan IFM 6 diekstraksi menggunakan pelarut etil asetat hingga diperoleh ekstrak etil asetat isolat supernatan IFM 2 dan IFM 6 alga merah jenis Gracilaria verrucosa. Ekstrak isolat supernatan IFM 2 dan IFM 6 dilakukan pengujian aktivitas antibiotika secara KLT-Bioautografi menggunakan fase gerak n-heksan : Etil Asetat (1:5). Hasil pengujian secara KLT-Bioatuografi diperoleh nilai $\operatorname{Rf} 0,07$; dan 0,81 aktif terhadap Bacillus subtilis dan Eschericia coli, nilai Rf 0,56; dan 0,81 aktif terhadap Shigella dysentriae, dan nilai $\operatorname{Rf} 0,23$; 0,78; dan 0,94 aktif terhadap Streptococcus mutans, ini membuktikan bahwa isolat fungi endofit pada Alga Merah jenis Gracilaria verrucosa berpotensi sebagai penghasil antibiotika.

Hasil iengidentifikasi komponen kimia aktif isolat fungi endofit IFM 2 dan IFM 6 dilakukan penyemprotan menggunakan pereaksi spesifik yaitu untuk mengidentifikasi adanya senyawa Alkaloid menggunakan pereaksi golongan dragendrof dan bauchardard, identifikasi senyawa fenol menggunakan pereaksi golongan $\mathrm{FeCl}_{3}$, dan identifikasi senyawa

flavonoid menggunakan pereaksi golongan sitroborat. Hasil penyemprotan pereaksi golongan pada isolat IFM 2 diperoleh bercak warna biru pada penyemprotan dragendrof, bercak berwarna coklat pada penyemprotan bauchardard, tidak memiliki perubahan warna pada penyemprotan $\mathrm{FeCl}_{3}$, dan flavanoid tidak terjadi perubahan warna flourosensi pada penyemprotan sitroborat yang divisualisasi pada lampu UV $366 \mathrm{~nm}$, dan isolat IFM 6 diperoleh bercak warna biru pada penyemprotan dragendrof, bercak berwarna coklat pada penyemprotan bauchardard, tidak memiliki perubahan warna pada penyemprotan $\mathrm{FeCl}_{3}$, dan untuk flavanoid tidak terjadi perubahan warna flourosensi pada penyemprotan sitroborat yang divisualisasi pada lampu UV 366 nm. Dari hasil penyemprotan maka diketahui isolat IFM 2 dan isolat IFM 6 positif memiliki senyawa alkaloid ditandai dengan adanya bercak berwarna coklat pada penyemprotan pereaksi bauchardard.

\section{KESIMPULAN}

Isolat fungi endofit IFM 2 dan IFM 6 merupakan isolat dengan diameter terbesar menghambat pertumbuhan bakteri Streptococcus mutans sebesar $25 \mathrm{~mm}$ dan secara KLT-Bioautografi dengan nilai $\operatorname{Rf} 0,07$ dan 0,81 aktif 
Isolasi fungi endofit penghasil antibiotika pada alga merah jenis Gracilaria verrucosa secara $K L T$-Bioautografi

terhadap Bacillus subtilis dan

Eschericia coli, nilai Rf 0,56 ; dan 0,81

aktif terhadap Shigella dysentriae, dan

nilai $\operatorname{Rf} 0,23$; 0,78; dan 0,94 aktif

terhadap Streptococcus mutans. Isolat

IFM 2 dan IFM 6 positif memiliki

golongan senyawa alkaloid ditandai

dengan adanya bercak berwarna coklat

pada penyemprotan pereaksi

bauchardard.

\section{DAFTAR PUSTAKA}

1. Neu $\mathrm{CH}$. The crisis in antibiotic resistence.Science.1992;257:10641073.

2. Tscherter $\mathrm{H}$, Dreyfuss. New Metabolites, Processes for Their Production and Uses. International Application Published Under The Patent Cooperation Treaty (PCT). International Publication.1992;38: 28-45.

3. Kauffman CA, Carver PL. Antifungal agents in the 1990s. Current status and future developments (Review). Drugs. 1997;53:539-549.

4. Rante, et al. Isolasi fungi endofit penghasil senyawa antimikroba dari daun katakokkon (Capsicum annuun $L$ var.chinensis) dan profil KLT-Biauotografi. Majalah Farmasi dan Farmakologi.2013;17(2):39-46.

5. Rante, et al. Isolasi fungi endofit penghasil antibiotika dari Kappaphycus alvarezzi Doty asal Kabupaten Takalar. Makassar : Fakultas Farmasi, Universitas Hasanuddin, 2010.

6. Alwiyah T. Isolasi fungi endofit sebagai penghasil antibiotika dari rimpang tanaman kunyit kuning (Curcuma Domestica Linn.) dan kunyit putih (Kaempferia rotunda Linn.) (Skripsi). Makassar: Fakultas Farmasi, Universitas Muslim Indonesia, 2012.

7. Djide MN. Analisis Mikrobiologi Farmasi. Makassar : Fakultas MIPA. Universitas Hasanuddin, 2005. 